\title{
Magnitude of physiological curvatures of the spine and the incidence of contractures of selected muscle groups in students
}

\author{
Elżbieta Olszewska, Piotr Tabor, Renata Czarniecka \\ Faculty of Physical Education, Józef Pilsudski University of Physical Education, Warsaw, Poland
}

\section{Summary}

Study aim: The aim of this study was to evaluate the incidence of contractures of selected muscle groups with respect to the magnitude of the physiological curvatures of the spine in young men with above-average levels of physical activity.

Material and methods: The study included 96 students at the University of Physical Education in Warsaw aged between 20 and 22 years $(21.2 \pm 1.05)$. Ninety-five percent of the students participated in sports training activities. The study was conducted between January and February 2016. The selected traits of the body posture were evaluated with an inclinometer, which was used to measure the inclination angles of sections of the spine relative to the vertical. The ranges of motion in the shoulder complex and the pelvic complex were measured with a goniometer. Values of $175^{\circ}$ (for the shoulder complex) and $174^{\circ}$ (for the hip joint) were assumed to indicate a decreased range of motion.

Results: The analysis of the individual results concerning mobility disorders in the shoulder complex and the pelvic complex revealed significant abnormalities in the researched group of students. About $90 \%$ of the study participants showed contractures of selected muscle groups within the shoulder girdle, primarily in the right upper limb. Similar results were obtained for the incidence of contractures in the flexors of the hip joint. Flexion contractures in the hip joint were observed in around $84 \%$ of the participants, primarily in the left lower limb. The correlations between the inclination angles of the sections of the spine relative to the vertical and the ranges of motion in the shoulder complex and the pelvic complex, established using Pearson correlation coefficients, were ambiguous. The angles $\gamma, \beta_{1}$ and $\alpha$ were inversely proportional to the range of raising motions of the upper limbs through flexion, where the correlation coefficients of all angles were statistically significant. Similar tendencies were observed for the correlations between the angles $\beta_{2}, \beta_{1}$ and $\alpha$ and the range of the extension movements at the hip joint, although the correlation coefficients were statistically significant only in the case of the angle $\beta_{1}$.

Conclusions: Ranges of movement in the shoulder complex and pelvic complex have an influence on magnitude of physiological curvatures of the spine and the functioning of body posture.

\section{Key words: Body posture - Tension of the postural muscle - Physiological curvatures}

\section{Introduction}

Body posture is the outcome of several factors, both internal (the structure of the osseo-ligamentous apparatus, tension of the postural muscles, functioning of the nervous system and integration of the senses) and external (the environment where a person lives, working and learning conditions and the level of physical activity) [8]. Evaluating a person's body posture is difficult despite the existence of established criteria for determining correct posture and anatomical traits (the structure of the spine, shoulder girdle and pelvis, and the presence of physiological curvatures of the spine). But although there are many methods used to evaluate the anatomical traits of body posture, it is nonetheless difficult to analyse 'one's postural tendencies' [1]. If we adopt the definition of body posture as 'one's postural tendencies', the analysis of the body posture should take into consideration not only the positioning of the body segments, but also, and perhaps first and foremost, the functional state of the body posture. The condition required for maintaining a vertical posture is correct distribution of the tension in the antagonistic muscles. Here, the postural muscles must be active enough to oppose the force of gravity, but not so active as to generate an excessive energy cost. The structure of the human body is such that the postural tension is distributed globally, rather than being focused locally [5, 6, 8, 23, 29]. 
The most frequent disorders of body posture in children and youths occur due to incorrect tension of the postural muscles (muscle dystonia), which may lead to contractures of some groups of muscles becoming permanent and to other muscles stretching (antagonistic muscles). Disorders related to the distribution of the tension in the postural muscles can also restrict the mobility of the joints. In adult persons, muscle dystonia results in excessive strain on the musculoskeletal system, and frequently pain $[2,6,13,14]$. Due to the above, maintaining the appropriate degree of muscle flexibility and the optimal physiological ranges of motion in the joints will determine the correct functioning of the body and the correct musculoskeletal fitness [4].

Muscle contractures cause motion in the joints, but whether such motions take place in their full range depends on many factors, including the conditions of the muscles [21]. Nonetheless, it should be mentioned that achieving excessive mobility in the joints (exceeding the physiological norms) may be undesirable and may lead to serious consequences. Such a state can lead to excessive relaxation (instability) of the joints, which may cause a higher risk of injuries [27]. At the same time, a limited range of motion in the joints, which sometimes co-occurs with muscle contractures, also brings a risk of injuries [27]. Muscle contractures can have many causes. They may result not only from a lack of physical activity, but also from training loads that are inappropriate for the actual capabilities of an exercising person. Contractures may lead to joint deformations and the loss of muscle functions, which in turn results in incorrect functioning of the upper limbs, lower limbs and the trunk.

The aim of this study is to evaluate the incidence of contractures in selected muscle groups with respect to the magnitude of the physiological curvatures of the spine in young men - students of physical education at the Academy of Physical Education in Warsaw.

\section{Material and methods}

The study participants comprised 96 men aged between 20 and 22 years $(21.2 \pm 1.05)$. Young men were students of the first or second year of physical education subject at the Academy of Physical Education in Warsaw. The assignment of students to this group was not accidental; participants of this study had to be students of physical education and they had to agree to participate in the body posture tests.

Students had obligatory physical exercises during the study every day, and in addition undertook other forms of activity physical during the week. Ninety-five percent of the studied men participated in sports training activities. The mean body height of the students was $180.4 \pm 6.7 \mathrm{~cm}$, and the mean body weight was $77.9 \pm 87.5 \mathrm{~kg}$. Their BMI was also calculated, and the results were as follows: $65.6 \%$ of the students had a normal BMI for men, whereas $34.3 \%$ showed a BMI between 25 and 29.5, which may indicate being overweight. However, it should be stressed that all the participants were second-year students of Physical Education, and that the BMI is not a good measure of the body shape type, especially in those persons who engage in competitive sport, because it does not take the body's musculature into account.

The study obtained a positive opinion of the Bioethical Commission at the Academy of Physical Education. The study was conducted between January and February 2016.

\section{Measurements of selected traits of body posture}

Selected traits of body posture were evaluated with an inclinometer (AMI), which was used to measure the inclination angles of sections of the spine relative to the vertical. The figure below shows the measured points.

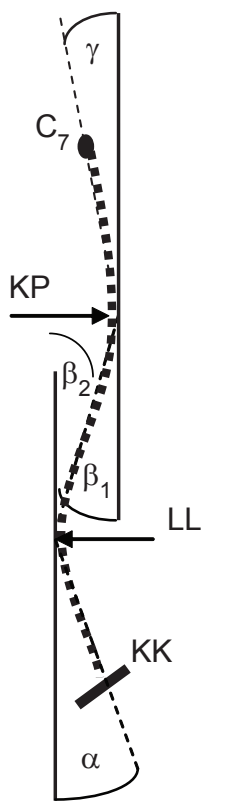

$$
\begin{aligned}
& \mathrm{C}_{7} \text { - cervical vertebra } \mathrm{C}_{7} \text {, } \\
& \mathrm{KK} \text { - sacra bone, } \\
& \mathrm{KP} \text { - top of thoracis kyphosis, } \\
& \mathrm{LL}-\text { top of lumbar lordosis, } \\
& \text { angle } \gamma \text { - inclination of the upper thoracic } \\
& \text { section relative to the vertical, } \\
& \text { angle } \beta_{1} \text { - inclination angle of the lower } \\
& \text { thoracic section relative to the vertical, } \\
& \text { angle } \beta_{2} \text { - inclination angle of the upper } \\
& \text { lumbar section relative to the vertical, } \\
& \text { angle } \alpha \text { - inclination angle of the lower } \\
& \text { lumbar section relative to the vertical }
\end{aligned}
$$

Fig. 1. Measurements of the inclination angles of sections of the spine relative to the vertical

The measurements of the angles $\alpha, \gamma, \beta_{2}$ and $\beta_{1}$ were used to calculate the magnitude of the physiological curvatures of the spine according to the following formulas [22]:

$$
\mathrm{KP} \text { angle }=180^{\circ}-\gamma-\beta_{1}, \quad \text { LL angle }=180^{\circ}-\alpha-\beta_{2},
$$

where $\mathrm{KP}$ - thoracis kyphosis angle, LL - lumbar lordosis angle.

\section{Measurements of the ranges of motion in the shoulder and the hip complexes}

The ranges of motion on the right and the left side were measured with a goniometer. The ranges of the raising motion of the upper limb through flexion were measured 
using the Dega test carried out in a supine position with the maximum possible flexion.

The contractures of the iliopsoas muscle were evaluated using the Thomas test carried out in a supine position with one lower limb extended to the maximum of the participant's capabilities, and the other lower limb flexed so as to stabilise the pelvis. After Kapandji [16], the study assumed that angular values below $175^{\circ}$ for the shoulder complex and below $174^{\circ}$ for the hip joint indicated a limited range of motion.

Differences in the ranges of movement between the lower and upper limbs on the right and left were tested with Student's t-test. Pearson's correlation coefficient was calculated to evaluation the relationship between ranges of motion in the shoulder complex and the pelvic complex and angles of inclination of spine sections relative to the vertical. The value $\mathrm{p} \leq 0.05$ was deemed as statistical significance level.

\section{Results}

Disorders of the range of motion in the shoulder complex and the pelvic complex can determine the magnitude of physiological curvatures of the spine. The correct functioning of the spine results from the optimal positioning of the shoulder girdle and pelvis, and their functional fitness. Table 1 presents the mean ranges of motion in the shoulder complex (the Dega test - for the contracture of the pectoral muscles) and the pelvic complex (the Thomas test - for the contracture of the iliopsoas muscle) in the left and the right sides of the researched students.

In the experimental group, the mean values of the ranges of motion in the shoulder complex indicated a limited degree of mobility (contracture of the pectoral muscles). This concerned both the right and the left upper limb. It should also be stressed that the study revealed the presence of asymmetric contractures in both of the upper limbs, and the difference was statistically significant (Table 1). Similar observations were made for the occurrence of limited ranges of motion in the hip joints (flexion contracture). The arithmetic mean revealed the occurrence of a limited range of extension movements at the hip joint. No significant differences were noted between the right and the left lower limbs.

An analysis of the individual results concerning motion disorders in the shoulder complex and the pelvic complex showed significant abnormalities among the researched students. Contractures of the selected muscle groups within the shoulder girdle were noted in around $90 \%$ of the participants, and these disorders more frequently concerned the right upper limb. Similar results were obtained for the incidence of contractures of the selected muscle groups within the pelvis. In this case, flexion contractures in the hip joint were observed in around $84 \%$ of the participants, and they more frequently concerned the left lower limb (Table 2).

Tension disorders in selected muscle groups within the shoulder complex and the pelvic complex may have a negative effect on the magnitude of the physiological

Table 1. Ranges of motion [deg] in the shoulder complex and the pelvic complex for the left and the right limbs of the researched students

\begin{tabular}{lccc}
\hline & Left & Right & Average \\
\hline & $162 \pm 9.31$ & $160.6 \pm 9.18^{* *}$ & $161.3 \pm 8.85$ \\
The shoulder complex & $\min =141$ & $\min =137$ & $\min =139$ \\
& $\max =180$ & $\max =180$ & $\max =180$ \\
\hline & $165.6 \pm 7,56$ & $166 \pm 7.03$ & $165.8 \pm 6.82$ \\
The pelvic complex & $\min =145$ & $\min =145$ & $\min =146$ \\
& $\max =175$ & $\max =178$ & $\max =175$ \\
\hline
\end{tabular}

$* * \mathrm{~T}=2.611, \mathrm{p}=0.010$.

Table 2. Incidence of contractures of selected muscle groups in the shoulder complex and the pelvic complex

\begin{tabular}{lcccccccc}
\hline & \multicolumn{4}{c}{ Right side } & \multicolumn{3}{c}{ Left side } \\
\cline { 2 - 9 } & \multicolumn{2}{c}{ Correct } & \multicolumn{2}{c}{ Contracture } & \multicolumn{2}{c}{ Correct } & \multicolumn{2}{c}{ Contracture } \\
\cline { 2 - 9 } & $\mathrm{N}$ & $\%$ & $\mathrm{~N}$ & $\%$ & $\mathrm{~N}$ & $\%$ & $\mathrm{~N}$ & $\%$ \\
\hline The shoulder complex - pectorals muscle & 7 & 7.3 & 89 & 92.7 & 11 & 11.5 & 85 & 88.5 \\
The pelvic complex - iliopsoas muscle & 18 & 18.8 & 78 & 81.3 & 12 & 12.5 & 84 & 87.5 \\
\hline
\end{tabular}


Table 3. Values of the inclination angles of the sections of the spine relative to the vertical and values of the angles that describe the magnitude of thoracic kyphosis and lumbar lordosis

\begin{tabular}{ccccccc}
\hline angles [deg] & $\gamma$ & $\mathrm{KP}$ & $\beta_{1}$ & $\beta_{2}$ & LL & $\alpha$ \\
\hline & $23 \pm 5.9 \min =9$ & $145 \pm 9.1$ & $12 \pm 5.0$ & $13 \pm 4.4$ & $155 \pm 7.0$ & $13 \pm 4.4$ \\
& $\max =38$ & $\min =116$ & $\min =0,5$ & $\min =3$ & $\min =137$ & $\min =3$ \\
& & $\max =169$ & $\max =26$ & $\max =24$ & $\max =166$ & $\max =26$ \\
\hline
\end{tabular}

$\gamma$-inclination of the upper thoracic section relative to the vertical, TK - thoracis kyphotic angle, $\beta_{1}$ - inclination angle of the lower thoracic section relative to the vertical, $\beta_{2}$ - inclination angle of the upper lumbar section relative to the vertical, LL - lumbar lordosis angle, and $\alpha$ - inclination angle of the lower lumbar section relative to the vertical.

curvatures of the spine. Table 3 shows the values of the inclination angles of sections of the spine relative to the vertical, which characterise the magnitude of the physiological curvatures of the spine.

The mean inclination angle of the upper section of the thoracic kyphosis $(\gamma)$ was $23 \pm 5.8^{\circ}$, and the mean value of the angle $\beta_{1}$ was $12 \pm 5.0^{\circ}$. It should be stressed that higher values of the angles $\gamma$ and $\beta_{1}$ are correlated with greater kyphotic curvature of the spine. The mean kyphotic angle in the researched students was $145^{\circ}$, with the minimum value of $116^{\circ}$ and the maximal value of $169^{\circ}$. Therefore, the magnitude of the thoracic kyphosis among the students varied significantly (Table 3 ).

The mean values of the angles $\alpha$ and $\beta_{2}$ in the participants were the same $\left(13 \pm 4.40^{\circ}\right)$. The mean value of the lumbar lordosis angle in the students was $155 \pm 7.0^{\circ}$ (Table 3).

While analysing the values of the angles $\beta_{1}$ and $\beta_{2}$, it was noted that the mean values of the two angles were similar. On the other hand, in the study significantly higher values were observed for the angle $\gamma$ in the participants than for the angle $\alpha$. These results may indicate that the researched students tended to have a greater thoracic kyphotic angle in comparison to the lumbar lordosis.

The correlations between the inclination angles of the sections of the spine from the vertical and the ranges of the selected motions in the shoulder complex and the pelvic complex, established using the Pearson correlation coefficient (Table 4), were ambiguous. Nonetheless, there existed an inversely proportional correlation between the angles $\gamma, \beta_{2}$ and $\alpha$ and the range of the raising motion of the upper limbs through flexion, where the values of the correlation coefficient were statistically significant (Table 4).

Similar tendencies were observed when analysing the correlations between the angles $\beta_{1}, \beta_{2}$ and $\alpha$ and the capacity for the extension movement in the hip joint (the contracture of the flexor muscles of the hip joint). In this case, the correlation coefficient was statistically significant only with respect to the angle $\beta_{2}$. The above results stand to reason, due to the correlation between the value of the kyphotic angle and the lumbar lordosis angle with respect to the discussed motion capabilities. Table 4 shows that there is a positive correlation between the angular values of the physiological curvatures of the spine and the motion

Table 4. Values of the Pearson correlation coefficient for the analysed variables and the levels of significance

\begin{tabular}{lcccccc}
\hline & Angle $\gamma$ & Angle $\beta_{1}$ & Angle KP & Angle $\beta_{2}$ & Angle $\alpha$ & Angle LL \\
\hline Shoulder complex - right side & -0.251 & -0.2622 & 0.2740 & -0.1997 & -0.2679 & 0.3339 \\
& $\mathrm{p}=0.014^{*}$ & $\mathrm{p}=0.010^{* *}$ & $\mathrm{p}=0.007^{* *}$ & $\mathrm{p}=0.051$ & $\mathrm{p}=0.008^{* *}$ & $\mathrm{p}=0.001^{* *}$ \\
Shoulder complex - left side & -0.1905 & -0.2027 & 0.1816 & -0.1040 & -0.2082 & 0.2588 \\
& $\mathrm{p}=0.063$ & $\mathrm{p}=0.048^{*}$ & $\mathrm{p}=0.077$ & $\mathrm{p}=0.313$ & $\mathrm{p}=0.042^{*}$ & $\mathrm{p}=0.011^{* *}$ \\
Shoulder complex - average & -0.2304 & -0.2427 & 0.2377 & -0.1583 & -0.2484 & 0.3094 \\
range of movement & $\mathrm{p}=0.024^{*}$ & $\mathrm{p}=0.017^{*}$ & $\mathrm{p}=0.020^{*}$ & $\mathrm{p}=0.124$ & $\mathrm{p}=0.015^{*}$ & $\mathrm{p}=0.002^{* *}$ \\
& 0.1055 & -0.1849 & -0.0383 & -0.0545 & -0.1230 & 0.1938 \\
Pelvic complex - right side & $\mathrm{p}=0.306$ & $\mathrm{p}=0.071^{*}$ & $\mathrm{p}=0.711$ & $\mathrm{p}=0.598$ & $\mathrm{p}=0.232$ & $\mathrm{p}=0.058$ \\
& 0.0478 & -0.2252 & 0.0513 & -0.1485 & -0.1494 & 0.2358 \\
Pelvic complex - left side & $\mathrm{p}=0.643$ & $\mathrm{p}=0.027^{*}$ & $\mathrm{p}=0.619$ & $\mathrm{p}=0.149$ & $\mathrm{p}=0.146$ & $\mathrm{p}=0.0218$ \\
Pelvic complex - average & 0.0809 & -0.2202 & 0.0087 & -0.1104 & -0.1463 & 0.2307 \\
range of movement & $\mathrm{p}=0.433$ & $\mathrm{p}=0.031^{*}$ & $\mathrm{p}=0.933$ & $\mathrm{p}=0.284$ & $\mathrm{p}=0.155$ & $\mathrm{p}=0.024 *$ \\
\hline
\end{tabular}

$*-\mathrm{p} \leq 0.05, * *-\mathrm{p} \leq 0.0$. 
capabilities in the discussed complexes. Thus, the limited ranges of the extension movement in the hip joint and the raising motion of the upper limbs through flexion are related to a tendency for the physiological curvatures of the spine to increase.

\section{Discussion}

A functional analysis of the body posture seems to provide a significant diagnostic element for fostering the correct functioning of the human body. For the diagnostics of pain in the musculoskeletal system, various tests are used to analyse the mobility in the joints and the tension of different muscle groups [8]. Most frequently, the body posture of children and youths is assessed with the Dega test, the Thomas test, the Matthias test, the Kraus-Weber test, the Schober test, the Patrick test, etc. [8].

In the present study, the ranges of selected motions in the shoulder and the pelvic complexes were evaluated with the Dega test and the Thomas test. The analysis of the incidence of contractures in the pectoral muscles (the Dega test) showed that around $90 \%$ of the participants had limited mobility in the arm-shoulder joints. The majority of the researched students who tested positive in the Dega test also had increased thoracic kyphosis. This tendency is well-documented in the literature $[10,19,20]$. In the study, a contracture of the pectoral muscles in those students who displayed a correct magnitude of thoracic kyphosis was also observed. It may be assumed that this state in the Physical Education students is a result of the sports training undertaken by them, as well as the additional physical activities. In many cases, these additional physical activities involved sports training based on exercises designed to build muscle mass. Nowadays, exercising in a gym is one of the most popular forms of physical activity among young people; however, these workouts do not always involve the appropriate proportions of strengthening exercises to stretching exercises.

The evaluation of the contracture of the flexor muscles of the hip joint (the Thomas test) showed that this issue concerned around $84 \%$ of the researched students. This result may be surprising, because the majority of the participants were actively engaged in sport and they did not display excessively increased lumbar lordosis with the anterior pelvic tilt. On the contrary, the study observed that about $13 \%$ of the participants had a tendency towards flattening of the lumbar lordosis in comparison to the thoracic kyphosis. It may be assumed that the incidence of the contractures in the hip joint, as well as the tendency toward a decrease of the lumbar lordosis in some of the students, is a result of the development of a compensation mechanism used during sports training (resulting from greater strain on the lumbar section of the spine).
The studies by other authors also indicate that disorders of the muscle tension in the form of contractures of selected muscle groups may also occur in those persons engaging in various forms of physical activity, both at the amateur and the professional level $[3,7]$. Contractures in the pectoral, iliopsoas and ischiocrural muscles, in students at the Academy of Physical Education in Katowice, concerned from 8 to $32 \%$ of the study participants (both women and men) [12]. Asymmetric contractures also occurred frequently in the cited studies, which caused a twisting of the shoulder girdle or the pelvis. The occurrence of an asymmetrical distribution of the tension in the selected muscle groups has been documented by many authors [7, 14, 15, 17, 24]. There are also some sport disciplines in which hypermobility of the joints is, in fact, desirable, such as artistic and sports gymnastics, or acrobatics [3].

The positioning, shape and mobility of the spinal joints, as well as the joints connecting the spine with the shoulder girdle and the pelvis, play a fairly important role in the context of correct body posture and a person's physical functioning $[12,25]$. Limited mobility in the shoulder complex and the pelvic complex is one of the factors that have a negative effect on the magnitude of the physiological curvatures of the spine. Having in mind that excessive tension of the pectoral muscles increases the degree of thoracic kyphosis, and that flexion contractures in the hip joints increase the lumbar lordosis, there is a need to diagnose these curvatures during an evaluation of the body posture [12, 32].

According to the study conducted among the secondyear students at the Academy of Physical Education in Warsaw, abnormalities of the body posture in the sagittal plane concerned around $80 \%$ of the participants. On the one hand, this result may be considered as surprising, because abnormalities in the magnitude of physiological curvatures of the spine are often identified with a sedentary lifestyle and limited amounts of physical activity. However, it should be stressed that excessive physical activity and specialist sports training may also cause abnormalities in the physiological curvatures of the spine.

Studies by many authors have confirmed that abnormalities of the physiological curvatures of the spine can occur in different groups of children and youths, including those involved in physical training. In these studies, the prevalence of increased physiological curvatures of the spine ranges between 15 and $70 \%$, depending on the researched group and the research method [18, 30, 31]. Abnormalities in the magnitude of the physiological curvatures of the spine also concern adult persons. A study by Zwierzchowska [32] conducted among students in the University of Economics in Rzeszów revealed that only $2.6 \%$ of the female students and $6.6 \%$ of the male students had correct body posture. Abnormalities in the 
body posture in the coronal plane were also observed by Rusek [26], who investigated students at the University of Rzeszów. Such a high percentage of abnormalities in the body posture in the sagittal plane is probably a result of the different research methodologies used in the studied groups; however, it seems that the main reason is a low level of physical activity among persons of different ages.

\section{Conclusions}

1. There is a need for further evaluation of the tension of the muscles in the shoulder girdle and the pelvic girdle that includes measurements of the left and the right side of the body.

2. Ranges of movement in the shoulder complex and pelvic complex have an influence on the magnitude of physiological curvatures of the spine and the functioning of body posture. The strength of the correlation between muscle contractures and the magnitude of the physiological curvatures of the spine indicates high importance of the tension at the myofascial meridians for maintaining the correct body posture.

\section{Conflict of interest: Authors state no conflict of interest.}

\section{References}

1. Ackland T.R., Elliot B.C., Bloomfield J. (2003) Applied anatomy and biomechanics in sport. Blackweel Publishing, Australian.

2. Andersson H.I., (1994) The epidemiology of chronic pain in a Swedish rural area. Qual. Life Res., 3(suppl.1): 19-26.

3. Baeza-Velasco C., Gély-Nargeot M.C., Pailhez G., Vilarrasa A. (2013) Joint hypermobility and sport: A review of advantages and disadvantages. Curr. Sport Med. Rep., 12(5): 291-295.

4. Ben M., Harvey L.A. (2010) Regular stretch does not increase muscle extensibility: a randomized controlled trial. Scand. J. Med. Sci. Sport, 20: 136-144.

5. Bonetti F., Curti S., Mattioli S., Mugnai R., Vanti C., Violante F., Pillastrini P., (2010) Effectiveness of a 'Global Postural Reeducation' program for persistent Low Back Pain: a non-randomized controlled trial. BMC Musculoskeletal Disord., 11: 285-299.

6. Castagnoli C., Cecchi F. Del Canto A., Paperini A., Boni R., Pasquini G., Vannetti F., Macchi C. (2015) Effects in short and long term of global postural reeducation (GPR) on chronic low back pain: a controlled study with one-year follow-up. Sci. World J. 2015: 271436.
7. Collinge R., Simmonds J. (2009) Hypermobility, injury rate and rehabilitation in a professional football squad a preliminary study. Phys. Ther. Sport, 10: 91-96.

8. D'Arezzo P. (2003) Posture Alignment. The missing link in health and fitness. Marcelina Mountain Press, Colorado Spring.

9. Domosławska D., Demczuk-Włodarczyk E. (2012) The assessment of selected somatic traits and motor organs in sportspeople suffering from back pain. Pol. J. Sport Med., 28(4): 233-244.

10. Frutuoso A.S., Diefenthaeler F., Aurelio Vaz M., De la Rocha Freitas C. (2016) Lower limb asymmetries in rhythmic gymnastics athletes. Int. J. Sports Phys. Ther., 11(1): 34-43.

11. Grabara M. (2008) Spine flexibility and the prevalence of the increased stiffness of shoulders and hip joints in youth female and male handball players. Pol. J. Sport Med., 24(5): 304-310.

12. Grabara M., Szopa J. (2001) Gibkość studentów wychowania fizycznego oraz ćwiczenia rozciagająco-relaksacyjne oparte o system hatha jogi. In: J. Ślężyńskiego (eds.) Efekty kształcenia i wychowania w kulturze fizycznej. AWF, Katowice, pp. 261-277.

13. Hazlett R.L., McLeod D.R., Hoehn-Saric R. (1994) Muscle tension in generalized anxiety disorder: Elevated muscle tonus or agitated movement? Psychophysiology, 31: 189-195.

14. Hoch M.C., McKeon P.O. (2011) Joint mobilization improves spatiotemporal postural control and range of motion in those with chronic ankle instability. J. Orthop. Res., 29(3): 326-332.

15. Hoy D., Brooks P., Blyth F., Buchbinder R. (2010) The Epidemiology of low back pain. Best Pract. Res. Cl. Rh., 24: 769-781.

16. Kapandji A. (2007) The Physiology of the Joints: Upper Limb v. 1, Lower Limp v.2: Annotated Diagrams of the Mechanics of the Human Joints. Elsevier Health Sciences, London.

17. Lanshammar K., Ribom E.L. (2011) Differences in muscle strength in dominant and non-dominant leg in females aged 20-39 years a population-based study. Phys. Ther. Sport, 12(2): 76-79.

18. Maciałczyk-Paprocka K., Stawińska-Witoszyńska B., Kotwicki T., Sowińska A., Krzyżaniak A., Walkowiak J., Krzywińska-Wiewiorowska M. (2017) Prevalence of incorrect body posture in children and adolescents with overweight and obesity. Eur. J Pediatr., 176(5): 563-572.

19. Maduri A., Pearson BL., Wilson SE. (2008) Lumbar-pelvic range and coordination during lifting tasks. J. Electromyogr. Kines., 18: 807-814.

20. Malmström E.M., Olsson J., Baldetorp J., Fransson P.A. (2015) A slouched body posture decreases arm mobility and changes muscle recruitment in the neck and shoulder region. J. Appl. Physiol., 115: 2491-2503. 
21. Moromizato K., Kimura R., Fukase H., Yamaguchi K., Ishida H. (2016) Whole-body patterns of the range of joint motion in young adults: masculine type and feminine type. J. Physiol. Anthropol., 35: 23.

22. Nowotny J., Gaździk T., Zawieska D., Podlasiak P. (2002) Photogrammetry: myths and reality. Ortop. Traumatol. Rehabil., 4(4): 498-502.

23. Nowotny J., Nowotny - Czupryna O., Brzęk A., Kowalczyk A., Czupryna K. (2011) Body posture and syndromes of back pain. Ortop. Traumatol Rehabil. 13(1): 59-71.

24. Purcell L., Micheli L. (2009) Low Back Pain in Young Athletes. Sports Health, 1(3): 212-222.

25. Parkin S., Nowicky A.V., Rutherford O.M., McGregor A.H. (2001) Do oarsmen have asymmetries in the strength of their back and leg muscles? J. Sports Sci., 19(7): 521-526.

26. Rusek W., Pop T., Glista J., Skrzypek J. (2010) Ocena postawy ciała u studentów w badaniu systemem Zebris. Przeglad Medyczny Uniwersytetu Rzeszowskiego 3: 277-288

27. Seckin U., Tur B.S., Yimaz O., Yagci I., Bodur H., Arasil T. (2005) The prevalence of joint hypermobility among high school students. Rheumatol. Int., 25(4): 260-263.
28. Watson A.W. (1995) Sports injuries in footballers related to defects of posture and body mechanics. J. Sports Med. Phys. Fitness, 35(4): 289-294.

29. Whitehead N.P., Weerakkody N.S., Gregory J.E., Morgan D.L., Proske U. (2001) Changes in passive tension of muscle in human and animals after eccentric exercise. J. Physiol., 533: 593-604.

30. Sands W.A., McNeal J.R., Penitente G., Murray S.R., Nassar L., Jemni M., Mizuguchi S., Stone M.H. (2015) Stretching the Spines of Gymnasts: A Review. Sports Med., 46(3): 315-327.

31. Wilmańska I., Paradecka A., Raczkowski J.W. (2015) The occurrence of the failure body posture of children at primary school. Fizjoterapia Polska, 4: 64-73.

32. Zwierzchowska A., Gawlik H., Dudek J., J Graca J., Palica D. (2008) Evaluation of body posture in first year students of the University of Economics in Katowice. Pol. J. Sport Med., 24: 37-44.

\section{Received 05.09.2017 \\ Accepted 29.01.2018}

(C) University of Physical Education, Warsaw, Poland 